\title{
Reward Learning Requires Activity of Matrix Metalloproteinase-9 in the Central Amygdala
}

\author{
Ewelina Knapska, ${ }^{1}$ Victoria Lioudyno, ${ }^{2}$ Anna Kiryk, ${ }^{2}$ Marta Mikosz, ${ }^{1}$ Tomasz Górkiewicz, ${ }^{1,3}$ Piotr Michaluk, ${ }^{2}$ \\ Maciej Gawlak, ${ }^{1}$ Mayank Chaturvedi, ${ }^{2}$ Gabriela Mochol, ${ }^{1}$ Marcin Balcerzyk, ${ }^{2}$ Daniel K. Wojcik, ${ }^{1}$ \\ Grzegorz M. Wilczynski, ${ }^{1}$ and Leszek Kaczmarek ${ }^{2}$ \\ ${ }^{1}$ Department of Neurophysiology, Nencki Institute of Experimental Biology, 02-093 Warsaw, Poland, ${ }^{2}$ Department of Molecular and Cellular Neurobiology, \\ Nencki Institute of Experimental Biology, 02-093 Warsaw, Poland, and ${ }^{3}$ Department of Biophysics, Warsaw University of Life Sciences, 02-776 Warsaw, \\ Poland
}

Learning how to avoid danger and pursue reward depends on negative emotions motivating aversive learning and positive emotions motivating appetitive learning. The amygdala is a key component of the brain emotional system; however, an understanding of how various emotions are differentially processed in the amygdala has yet to be achieved. We report that matrix metalloproteinase-9 (MMP-9, extracellularly operating enzyme) in the central nucleus of the amygdala (CeA) is crucial for appetitive, but not for aversive, learning in mice. The knock-out of MMP-9 impairs appetitively motivated conditioning, but not an aversive one. MMP-9 is present at the excitatory synapses in the CeA with its activity greatly enhanced after the appetitive training. Finally, blocking extracellular MMP-9 activity with its inhibitor TIMP-1 provides evidence that local MMP-9 activity in the CeA is crucial for the appetitive, but not for aversive, learning.

\section{Introduction}

The amygdala consists of several cytoarchitectonically welldefined and internally distinguishable nuclei (Pitkänen et al., 2000; Sah et al., 2003; Knapska et al., 2007). Phylogenetically and morphologically, one can discriminate two major subdivisions of the amygdalar complex: the dorsomedial and basolateral groups of nuclei (Johnston, 1923; Humphrey, 1936; McDonald, 1992; Roberts, 1992). To explain the functional organization of the amygdala, Wurtz and Olds (1963), taking into consideration the results of self-stimulation studies, proposed that the dorsomedial amygdala acts as a rewarding, and basolateral as a punishing, system. For the next decades, most of the studies focused on the involvement of the amygdala in negative emotions, revealing, for instance, important regional and molecular underpinnings of innate and acquired fear as well as fear acquisition and fear extinction (Shumyatsky et al., 2005; Gogolla et al., 2009; Riccio et al., 2009; Johansen et al., 2011). In contrast, less is known in this

Received Nov. 11, 2012; revised Aug. 5, 2013; accepted Aug. 6, 2013.

Author contributions: E.K., G.M., M.B., D.K.W., G.M.W., and L.K. designed research; E.K., V.L., A.K., M.M., T.G., P.M., M.G., M.C., and G.M. performed research; E.K., V.L., A.K., M.M., T.G., P.M., G.M., D.K.W., G.M.W., and L.K. analyzed data; E.K. and L.K. wrote the paper.

This work was supported in part by COST Action Grant BM0901, Polish Ministry of Science and Higher Education (E.K. and L.K.), and TEAM project from the Foundation for Polish Science (L.K.). E.K. was supported by the Foundation for Polish Science through its HOMING program. We thank Drs. Joel D. Richter and Jacek Jaworski for critically reading the manuscript.

The authors declare no competing financial interests.

Correspondence should be addressed to either of the following: Dr. Ewelina Knapska or Dr. Leszek Kaczmarek, Nencki Institute, 3 Pasteur Street, 02-093 Warsaw, Poland, E-mail: e.knapska@nencki.gov.pl or I.kaczmarek@nencki.gov.pl.

V. Lioudyno's present address: Institute of Experimental Medicine, St. Petersburg, Russia.

P. Michaluk's present address: University College London, London, United Kingdom.

M. Balcerzyk's present address: University of Seville, Seville, Spain.

DOI:10.1523/JNEUROSCI.5239-12.2013

Copyright $\odot 2013$ the authors $\quad 0270-6474 / 13 / 3314591-10 \$ 15.00 / 0$ regard about appetitive learning and the amygdala. There is, however, growing evidence to support a major role for this structure in processing of positive emotions (Holland and Gallagher, 2004; Murray, 2007; Morrison and Salzman, 2010). In particular, it has been proposed that the central nucleus of the amygdala mediates stimulus-response representations and conditioned motivational influences on behavior, whereas the basolateral amygdala is required for a conditioned stimulus to gain access to the current affective value of its specific unconditioned stimulus (Everitt et al., 2003).

The results obtained predominantly with lesion and electrophysiological methods suggested that the subregions of the amygdala, underlying appetitive and aversive learning, were essentially the same (Schoenbaum et al., 1998; Everitt et al., 2003; Paton et al., 2006; Belova et al., 2007). However, molecular imaging at the cellular resolution suggests that specific subnuclei of the amygdala are differentially activated in a behavior-specific manner (Savonenko et al., 1999; Knapska et al., 2006, 2007). Studies on expression of gene activity markers, such as c-fos, in response to different types of behavioral training have demonstrated that the central nucleus of the amygdala $(\mathrm{CeA})$ is intimately associated with instrumental appetitive learning in mice and rats (Knapska et al., 2006). In addition to being widely investigated as a marker of neuronal activity, expression of c-Fos has also been shown to be related to synaptic plasticity, learning, and memory, as there is growing body of evidence that the neurons expressing c-Fos undergo plastic changes (Kaczmarek, 1993; Koya et al., 2009; Bossert et al., 2011; Liu et al., 2012). Understanding of c-Fos-dependent molecular underpinnings of the synaptic plasticity may be achieved by following its transcriptionregulatory function (i.e., by identifying the genes it controls). Tissue inhibitor of matrix metalloproteinases-1 (TIMP-1) and 
matrix metalloproteinase-9 (MMP-9) have been documented to be c-Fos/AP-1 regulated at the transcriptional level, also in the activated neurons (Jaworski et al., 1999; Kaczmarek et al., 2002; Rylski et al., 2009; Ganguly et al., 2013; Kuzniewska et al., 2013). Both TIMP-1 and MMP-9 compose an extracellularly and extrasynaptically operating enzymatic system acting on extracellular matrix and cell adhesion molecules to affect synaptic plasticity, learning, and memory (Rivera et al., 2010; Huntley, 2012).

Considering all of the above, we have hypothesized that MMP-9 activity may play a role in the central amygdaladependent appetitive conditioning. Whereas we demonstrate herein support for this hypothesis, surprisingly, we also report that MMP-9 is dispensable for aversive learning. Moreover, unexpectedly, we have also discovered that blocking MMP-9 selectively in the central amygdala produces the same appetitive learning deficit as global, unconditional gene knock-out.

\section{Materials and Methods}

\section{Subjects}

MMP-9 homozygous knock-out mice on a C57BL/6 background were obtained from Dr. Z. Werb (University of California, San Francisco). These mice were bred with C57BL/6NtacF wild-type mice for at least two generations and then maintained and bred continuously with each other as heterozygotes for $>10$ generations. Their homozygous progeny (MMP- $9^{-/-}$and MMP- $9^{+/+}$mice) used in this study were always littermates derived from several breeding pairs. All of the experiments were performed with female 2- to 4-month-old mice. The animals were group-housed and maintained on a $12 \mathrm{~h} / 12 \mathrm{~h}$ light/dark cycle with water and food provided ad libitum. The animals were treated in accordance with the ethical standards of European (directive no. 86/609/EEC) and Polish regulations. All of the experimental procedures were approved by the Local Ethics Committee.

\section{Training in the IntelliCages}

Apparatus. Four IntelliCages, provided by New-Behavior AG (http://www.newbehavior.com), were used for the long-term monitoring of the behavior of group-housed animals. The system was located inside of a large standard rat cage (Galsworthy et al., 2005). In the corners of the housing cage, there were four operant learning chambers. The mice had access to the chamber provided via a tube. The tube was equipped with an antenna reading the transponder codes. The transponder was implanted subcutaneously to enable animal identification. Only a single mouse had access to one learning chamber at a time. The chamber was equipped with a proximity sensor and contained two openings that permitted access to the drinking bottle spouts. These openings were crossed by photobeams that recorded nosepoke responses. Access to the bottles was blocked by small motorized doors. Aversive stimulation was delivered in the form of an air-puff directed at the head of the mouse through tubing controlled by electric valves. Additionally, each cage contained a sleeping shelter in the center, onto which the animals could climb to reach the food. The entire four-cage setup of the IntelliCage system was controlled by a computer that recognized the visits, nosepokes, and tube lickings of the individual mice and delivered reinforcements in response to nosepokes according to preprogrammed schedules that depended on the assignment of the mice to different test groups within the same cage. The system ran continuously for several days.

Procedure. For the IntelliCage experiments, the mice were anesthetized by isoflurane inhalation and subcutaneously injected with glass-covered microtransponders (Trovan, ID-100). The passive transponder emitted a unique animal identification code when activated by a magnetic field. The mice were then group-housed with a maximum of 15 animals per cage. A session began with $48 \mathrm{~h}$ adaptation to the cage. During this time, the gates were open, and the animals had free access to water (simple adaptation [SA]). Simple adaptation was followed by a $48 \mathrm{~h}$ period during which the mice learned to open the gates that barred access to tap water from both openings by means of nosepokes (nosepoke adaptation [NA]). The mice then had access to water by means of nosepokes in all phases of the experiments.
In the place preference task, the mice were given access to the bottles that contained sweetened water ( $10 \%$ sucrose) on both sides of the corner that was the least preferred during the NA session. They had no access to water in the other three corners. In the place avoidance task, the mice received an air-puff ( 0.75 bar, $1 \mathrm{~s})$ when they performed a nosepoke in the corner that was the most preferred during the NA session. In this task, all of the bottles were filled with tap water.

Before the discrimination training, access to water was limited to one corner of the cage for at least $48 \mathrm{~h}$. This procedure allowed the formation of a preference for this corner. In the same corner, the mice were then given the choice between sweetened water (10\% sucrose; one of two bottles in the corner) and tap water (another bottle in the corner) or between quinine solution ( $0.3 \mathrm{M}$; bitter taste) and tap water. The mice had no access to water in the other three corners during the discrimination training. There was a small subpopulation of mice that clearly preferred quinine solution over tap water; such animals were excluded from further analyses.

Before the discrimination training with water as a reward, access to water was limited to one corner of the cage for $48 \mathrm{~h}$, and then to only one side of another corner. Additionally, one nosepoke opened the door for $5 \mathrm{~s}$. only. Because water for nondeprived animals is not so rewarding as sucrose solution, this procedure was designed to make water less accessible and thus more valuable.

$\beta$-Dystroglycan $(\beta-D G)$ cleavage experiments. In the appetitively motivated task, $\beta$-DG cleavage was analyzed in three groups of mice. The first group had access to sweetened water ( $10 \%$ sucrose) in one corner and tap water in the other three corners (place preference learning). The second group had access to sweetened water (10\% sucrose) in all four corners (sweetened water exposure). The third group had access to tap water in all four corners (control group). In the aversively motivated task, $\beta$-DG cleavage was analyzed in two groups of mice. The first group received air-puffs ( 0.75 bar, $1 \mathrm{~s})$ in one of four corners (place avoidance learning). The second group received no air-puffs (control group). Both groups were in the same cage and had access to water in all four corners. The third set of animals was subjected to the simplified place learning paradigm. The mice had access to two corners in the cage (the other two corners were removed from the cage). Following standard SA and NA phases, the mice were deprived of water for $12 \mathrm{~h}$ and then either had access to sweetened water ( $10 \%$ sucrose) in one corner and tap water in another corner (place preference learning) or received air-puffs $(0.75$ bar) in one of two corners (place avoidance learning) or had access to water in both corners (control group). Temporary water deprivation evoked intense consummatory activity during a limited time and thus allowed the observation of the effects of learning in the $\beta$-DG cleavage analysis.

PLGA nanoparticle experiment. The animals were first adapted to the IntelliCages (SA and NA phases) and then underwent surgery. After $3 \mathrm{~d}$ of recovery, they were returned to the same IntelliCage and trained according to the procedure described above.

Behavioral data analysis. The numbers of visits, nosepokes, and tube lickings were analyzed in individual mice within defined periods of time. Additionally, to assess temporal changes in learning processes, the probabilities of nosepoke responses in the reinforced sides of the corners were calculated in the subsequent time windows for each mouse. A $6 \mathrm{~h}$ sliding window was moved with $60 \mathrm{~s}$ resolution throughout the duration of the experiment. In the consecutive sweeps of the window, the number of nosepokes in each side of the corner that contained sucrose or quinine solutions was calculated. The quotient of the number of nosepokes in the reinforced side that contained sucrose or quinine solution divided by the total number of nosepokes performed in this corner (reinforced side plus nonreinforced side) gave the probability of nosepoke responses in the reinforced sides within a given sweep. Each sliding window of time was centered in the middle of the $6 \mathrm{~h}$ period. The probability from the first $6 \mathrm{~h}$ of the experiments was ascribed to the third hour of the experiment. To smooth the curves, we used a $50 \mathrm{~min}$ filter. The probability of nosepoke responses in the reinforced sides of the corner was separately computed for each mouse and averaged over the entire sample of mice of the same genotype (MMP-9 $9^{-/-}$and MMP- $9^{+/+}$). All of the above analyses were performed with MATLAB (The MathWorks). To assess place memory 
during the discrimination training, percentage of visits that began with the correct response (to the bottle with sucrose solution or tap water in the appetitively motivated training) or with the incorrect response (to the bottle with quinine solution in the aversively motivated training) during the subsequent phases of learning was analyzed. The discrimination scores were compared with the level of chance (50\%).

\section{Open field test}

The apparatus had a wooden floor $(59.5 \times 59.5 \mathrm{~cm})$ surrounded by walls (34 cm height) that were painted gray. The animals' behavior was monitored by a video camera placed above the center of the apparatus. The mice were individually placed in one corner of the open field facing the corner and allowed to freely explore the apparatus for $5 \mathrm{~min}$. The floor of the apparatus was cleaned with ethanol after each session. To analyze behavior, the open field apparatus was divided into three virtual zones: thigmotaxic, middle (each $12 \mathrm{~cm}$ wide), and center. The data were analyzed using the EthoVision system (Noldus Information Technology), and the following parameters were counted: total time spent in each zone, frequency of passing through each zone, and latency of the first occurrence in each zone.

\section{$\beta-D G$ cleavage}

To assess the enhanced MMP-9 activity, $\beta$-DG cleavage quantitative immunoblot assay was used. $\beta$-DG, a substrate of MMP- 9 , is cleaved in the activated neurons and the level of its cleavage reflects MMP-9 activity (Michaluk et al., 2007). $\beta$-DG cleavage was analyzed in the entire amygdala as well as in the central amygdala (CeA) alone after either appetitive or aversive training. The brains were harvested $0-0.5 \mathrm{~h}$ after the training and immediately frozen on dry ice. Thick brain sections (1.0 $\mathrm{mm}$ ) from one hemisphere (for the entire amygdala) or both hemispheres (for the CeA) were cut, and the entire amygdala or CeA were isolated according to a mouse brain atlas. The CeA was manually dissected from the brain slices. Western blot analysis was then conducted. Total protein extracts were prepared and subjected to immunoblotting according to a previously described procedure (Michaluk et al., 2007). For comparisons of $\beta$-DG levels in animals subjected to different types of behavioral stimulation, $\beta$-DG/GAPDH ratios were calculated.

\section{In situ zymography and immunofluorescence}

In situ zymography was performed in 6- $\mu \mathrm{m}$-thick sections of the brain tissue embedded in polyester wax. The only modification of the procedure described previously (Wilczynski et al., 2008; Gawlak et al., 2009) was the use of DQ-gelatin coupled to Atto-647N (made upon request by Invitrogen) instead of the commercially available substrate. After zymography, the immunofluorescence reaction was performed with a rabbit antibody against postsynaptic density protein-95 (PSD95; a generous gift from Dr. Andreas Jeromin, Miami Children's Brain Institute, Miami, FL) followed by Alexa-555-coupled secondary antibody. Images were taken by sequential scanning with a Leica TCS SP 5 confocal microscope using HeNe $633 \mathrm{~nm}$ and DPSS diode $561 \mathrm{~nm}$ for the imaging of DQ-gelatin and PSD95, respectively.

\section{Formulation of poly(DL-lactide-co-glycolide)} (PLGA) nanoparticles

To investigate the role of MMP-9 activity in the CeA, we used nanoparticles (NPs) that slowly release TIMP-1, the endogenous MMP-9 inhibitor (Chaturvedi et al., 2012). TIMP-1-loaded PLGA NPs (MW 45,00075,000; copolymer ratio, 50:50; Sigma-Aldrich) were synthesized by multiple emulsion and the solvent evaporation method. Briefly, $100 \mathrm{mg}$ of PLGA NPs (50:50) and $4 \mathrm{mg}$ of dimethyl tartaric acid (Sigma-Aldrich) were dissolved in $5 \mathrm{ml}$ dichloromethane. Dimethyl tartaric acid was used to facilitate the release of encapsulated enzymes from the NPs. TIMP-1 (1 $\mathrm{mg}$ ) and $1 \mathrm{mg}$ BSA (Sigma-Aldrich) were dissolved in $500 \mu \mathrm{l}$ water. BSA was used in the present formulation to stabilize the encapsulated enzyme from interfacial inactivation. The protein solution was emulsified using a probe sonicator by dissolving dichloromethane that contained PLGA to make a primary emulsion that was further emulsified in $20 \mathrm{ml}$ of $1 \%$ polyvinyl alcohol (average MW 30,000-70,000; Sigma-Aldrich) solution in water. This multiple emulsion was stirred overnight to evaporate dichloromethane, and NPs were collected by centrifugation at $10,000 \times g$.
The NPs were washed three times with water, and the supernatant was collected for protein loading analysis.

\section{Characterization of PLGA nanoparticles}

TIMP-1 NPs were characterized using scanning electron microscopy, transmission electron microscopy, and dynamic light scattering to determine the Poly Dispersity Index, the Zeta potential, protein loading, and drug release (data not shown). To study TIMP-1 activity in NPs, we performed release studies. Briefly, $\sim 10 \mathrm{mg}$ of TIMP-1-loaded NPs was incubated with $1 \mathrm{ml}$ of PBS ( $\mathrm{pH} 7.4,154 \mathrm{~mm}$ ) in a $1.5 \mathrm{ml}$ Eppendorf tube at $37^{\circ} \mathrm{C}$. Three replicate tubes were used for each time point, and the tubes were sampled at various time points. The samples were centrifuged at 13,000 rotations per minute using a microcentrifuge (Eppendorf 5415R) for $15 \mathrm{~min}$. The supernatant from each of the above samples was analyzed using an EnzChek Gelatinase/Collagenase Assay kit (Invitrogen, E12055). In this assay, dye-quenched (DQ) gelatin was used as a substrate for MMP-9. When DQ gelatin was cleaved, it had fluorescence that was quantified using a microplate reader. Incubation was performed at room temperature while protecting from light. The fluorescence signal, reflecting proteolytic activity, was measured using a Molecular Devices SpectraMax M5e microplate reader (Software SpectraMax Pro 4.8) at 495/515 nm. For each time point, background fluorescence was corrected by subtracting the values of the nonenzymatic control.

\section{Surgery}

All of the surgical instruments were sterilized before surgery. The mice received butorphanol premedication $(0.2 \mathrm{mg} / 100 \mathrm{~g}$, subcutaneously) and were anesthetized with isoflurane. Ocular lubricant was used to moisten the eyes. After being placed into the stereotaxic apparatus (Stoelting), the scalp was shaved and disinfected with 70\% alcohol, incised, and retracted. Two small burr holes were drilled to allow for a Hamilton syringe needle ( $2.5 \mu \mathrm{l} ; 22$-gauge needle) to be lowered into the CeA (anterior/posterior, $-0.11 \mathrm{~cm}$; medial/lateral, $\pm 0.25 \mathrm{~cm}$; dorsal/ ventral, $-0.52 \mathrm{~cm}$ ). Infusions were performed by pressure injection with a Hamilton syringe (MicroSyringe Pump, World Precision Instruments; $0.5 \mu \mathrm{l}$ total volume, $100 \mathrm{nl} / \mathrm{min}$ for $5 \mathrm{~min}$ ). The needle remained in place for another $5 \mathrm{~min}$ to allow for the diffusion of the injected particles. After the injection, the incision was sutured and treated with antibiotic ointment, and the animals received an analgesic (Tolfedine, $4 \mathrm{mg} / \mathrm{kg}$; subcutaneously). To avoid dehydration, the animals were given $1 \mathrm{ml}$ of warm $0.95 \% \mathrm{NaCl} / 100 \mathrm{~g}$ body weight by subcutaneous injection. The mice were kept on a heating pad until they recovered from anesthesia before being returned to their home cages. The animals were allowed $3 \mathrm{~d}$ for postoperative recovery.

\section{Visualization of PLGA nanoparticles in the brain}

After the termination of the behavioral experiment, the NP-infused mice were deeply anesthetized with sodium pentobarbital $(100 \mathrm{mg} / \mathrm{kg})$ and perfused with ice-cold PBS, followed by $4 \%$ PFA. The brains were collected, fixed overnight in $4 \% \mathrm{PFA}$ at $4^{\circ} \mathrm{C}$, and impregnated in $30 \%$ sucrose. Subsequently, the brains were cut into coronal sections $(40 \mu \mathrm{m})$, and sections that contained the needle trace were collected. After three washes in PBST (PBS with Tween 20), the free-floating sections obtained from TIMP-1 NP-infused mice were incubated overnight at $4^{\circ} \mathrm{C}$ with the primary antibody to anti-6xHis tag (ab9108, Abcam) dissolved 1:200 in PBST that contained 3\% normal goat serum. Afterward, the sections were washed three times in PBST and incubated for $2 \mathrm{~h}$ at room temperature in AlexaFluor-568-labeled goat anti-rabbit IgG (A-11011, Invitrogen) dissolved 1:200 in PBST. Finally, after three washes in PBS, the sections were transferred to microscope slides and mounted using Vectashield Hard Set (Vector Laboratories). Control ("empty") NPs contained fluorescent 6-coumarine; thus, the sections that contained the infusion site obtained from the control NP-infused mice were transferred to microscope slides and mounted using Vectashield Hard Set (Vector Laboratories). The immunofluorescence of 6xHis-tagged TIMP-1 NPs and fluorescence of the empty NPs were used to confirm NP delivery and assess their distribution. Images were captured using a charge-coupled device camera-equipped fluorescent microscope (Nikon Eclipse 80). 
Statistical analyses

When appropriate, the data were statistically analyzed using one- and two-way ANOVA or repeated-measures ANOVA followed by the Fisher Least Significant Difference (LSD) post hoc test. Datasets that did not meet the criteria for parametric analyses were subjected to appropriate nonparametric tests. Within-group comparisons were performed using the Friedman ANOVA, followed by the Wilcoxon matched-pairs test. Between-group comparisons were performed using the Kruskal-Wallis ANOVA, Mann-Whitney $U$ test, and Kolmogorov-Smirnov test. To compare discrimination scores with the level of chance, a Wilcoxon signed-rank test was used. To compare MMP-9 activity blocked by TIMP-1 NPs, a $t$ test (twosample, assuming unequal variance) was used. The criterion for statistical significance was a probability level of $p<0.05$.

\section{Results}

MMP-9 is critical for appetitive, but not for aversive, learning

In the first experiment, MMP-9-null mutant (MMP-9 ${ }^{-1-}$ ) mice and their wildtype siblings (MMP-9 ${ }^{+/+}$) were exposed to a place preference and place avoidance training. To balance appetitive and aversive conditions, we used an automated test system (IntelliCage) that allows for assessing both spatial and operant behavior, as described previously (Galsworthy et al., 2005; Knapska et al., 2006). In the place preference test, the mice were supposed to learn that sweetened water was accessible by nosepoking in only one of the four corners within the large cage (i.e., the "correct" corner), whereas in the aversive training, they were learning to avoid a corner, in which nosepokes were punished with an air-puff. MMP- $9^{-/-}$mice emitted fewer nosepokes in the correct corner than MMP- ${ }^{+/+}$mice (Fig. $1 A$ ). In contrast to appetitively motivated place learning, no differences in aversive learning were observed between MMP-9 ${ }^{-1-}$ and MMP- $9^{+/+}$mice (Fig. 1C). To exclude the possibility that the obtained results were affected by impaired attention, perception, or motivation for the sweetened water reward, we additionally performed the place preference test with tap water as a reward. Because water for nondeprived animals is not so rewarding as sucrose solution, to make water less accessible and thus more valuable, it was accessible only in one side of the corner. The obtained results mirrored the results of learning with sucrose solution as a reward (Fig. $1 B$ ). To expose the mice to another pair of well-balanced appetitive versus aversive learning conditions, we have developed a novel training paradigm that, in contrast to the previous one, was less spatial in nature and relied on a different kind of aversive reinforcement. Thus, in the second experiment, the mice had to discriminate between bottles (placed on two sides of the same corner) that contained either sweetened or tap water (i.e., an appetitive task, Fig. 2A) or either bitter (quinine-adulterated) or tap water (i.e., an aversive task, Fig. 2D).
In the appetitive task, MMP- $9^{+/+}$mice began to acquire a preference for the side of the corner with sweetened water at the beginning of the training, reaching performance levels close to $100 \%$ at the third day of the training. In contrast, MMP-9 ${ }^{-1-}$ mice did not acquire the preference, staying at the last day of the training close to the chance (50\%) level (Fig. 2B). The rapid acquisition of the conditioned response and less variable performance in MMP- $9^{+/+}$mice, compared with MMP-9 ${ }^{-1-}$ mice, was reflected by a steeper and more stable learning curve (Fig. $2 C)$. Importantly, the lack of significant differences between the MMP- $9^{-/-}$and MMP- $9^{+/+}$mice in the overall number of nosepokes (Fig. $2 G$ ) disfavors nonlearning explanations of the observed results (e.g., impaired motivation).

In the aversive task, no difference between MMP-9 ${ }^{-1-}$ and MMP- $9^{+/+}$could be observed both as far as the average day-by- 
A

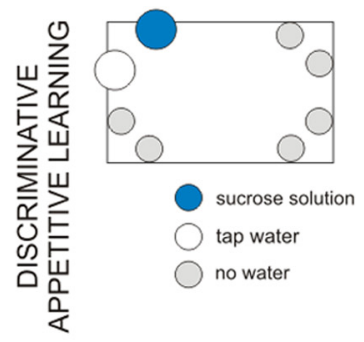

D

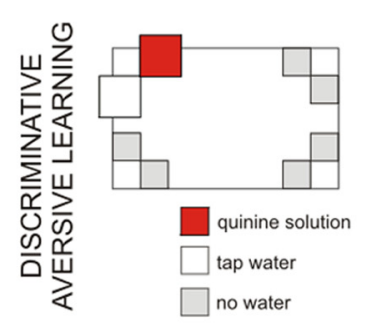

G

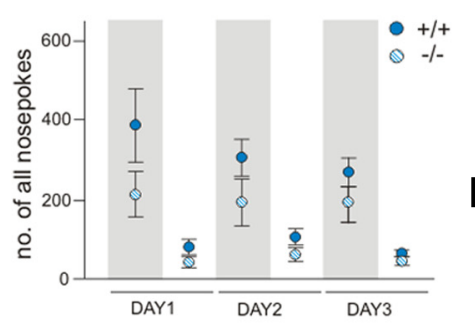

B

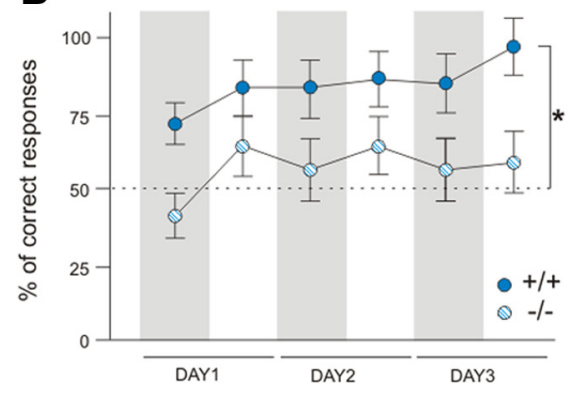

E

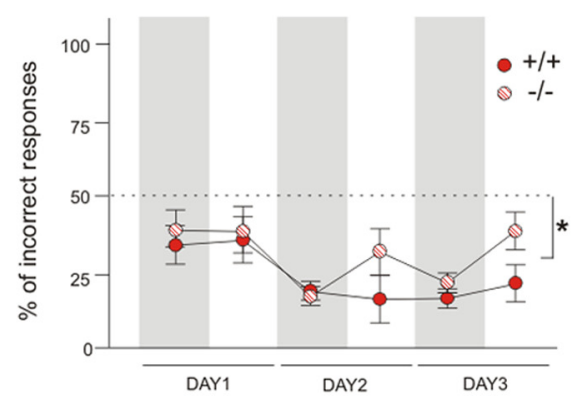

H
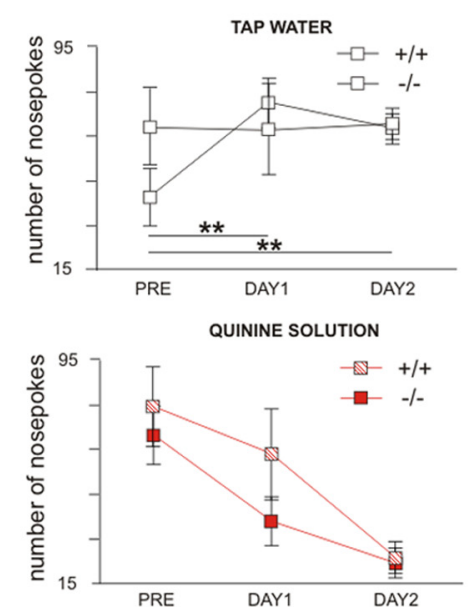

C

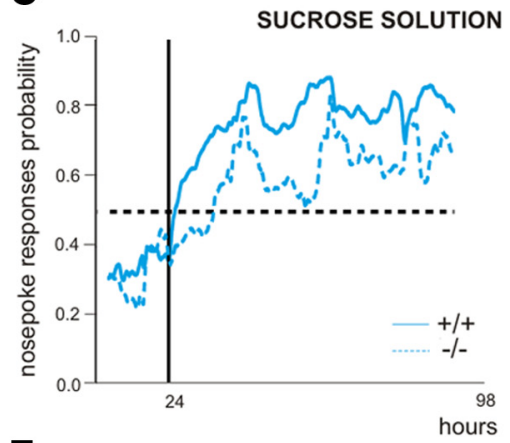

F

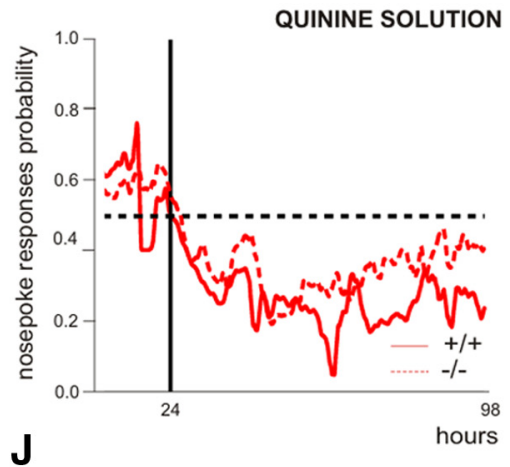

K

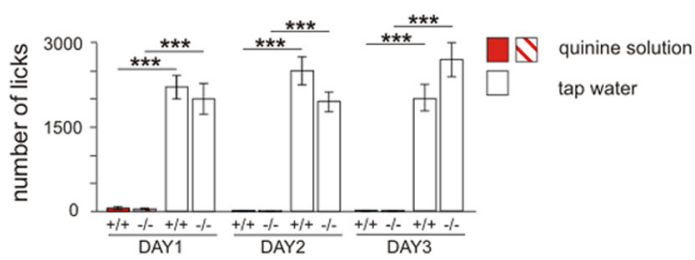

Figure 2. Appetitively, but not aversively, motivated discrimination learning by MMP- $9^{-1-}$ mice is deficient in the IntelliCage. $A$, In the appetitively motivated discrimination task, the mice were given a choice between sweetened water and tap water in two bottles placed in the same corner. $\boldsymbol{B}$, Percentage of visits that began with the correct response (to the bottle with sweetened water) made by MMP- $9^{-1-}(n=7)$ and MMP- $9^{+/+}$mice $(n=8)$ during the subsequent phases of the appetitively motivated discrimination learning (measure assessing place memory). The discrimination scores were above the level of chance only in MMP- $9^{+/+}$(Wilcoxon signed-rank test). To better present the learning dynamics, the results are presented separately for the day and night phases, and gray shaded areas represent the periods of the experiment when the lights were off. C, The learning curves indicate the probability of performing nosepokes in the reinforced side of the corner. The vertical black line indicates the introduction of sweetened water. MMP- $9^{+/+}$mice began to acquire a preference as early as the first day of appetitive training, whereas MMP- $9^{-1-}$ mice did not reach a significant difference between the numbers of nosepokes that provided access to sweetened water and tap water until the third day of the training: one-way ANOVA (genotype) with repeated measures (session and drinking solution), genotype $\times$ drinking solution interaction $\left(F_{(1,13)}=6.03, p<0.03\right.$, Fisher Least Significant Difference post hoc test); MMP-9 ${ }^{+/+}$mice for days 1,2 , and $3(p<0.0001)$; MMP- $9^{-1-}$ mice for day $3(p<0.03)$. , In the aversively motivated discrimination task, the mice were given a choice between quinine (bitter, aversive) solution and tap water in two bottles placed in the same corner. $\boldsymbol{E}$, Percentage of incorrect responses (visits that began with response to the bottle with quinine solution) emitted by MMP- $-9^{+/+}$and MMP- $9^{-1-}$ mice in the subsequent phases of training. The discrimination scores were above the level of chance for both MMP- $9^{+/+}(n=8)$ and MMP- $9^{-1-}$ mice $(n=7$; Wilcoxon signed-rank test). The gray shaded areas represent the periods of the experiment when the lights were off. $\boldsymbol{F}$, The learning curves depict the probability of performing nosepokes in the reinforced side of the corner. The vertical black line indicates the introduction of quinine solution. MMP- $9^{-/-}$mice learned to avoid the bitter taste at the same rate as MMP- $9^{+/+}$mice: one-way ANOVA (genotype) with repeated measures (session and drinking solution). The dashed lines indicate the chance level of a correct nosepoke response (50\%). G, Overall number of nosepokes performed in the subsequent phases of appetitively motivated discrimination training did not significantly differ between MMP- $9^{+/+}$and MMP- $9^{-I-}$ mice (Mann-Whitney $U$ test). $\boldsymbol{H}, \boldsymbol{I}$, MMP- $9^{+/+}$mice in parallel decreased the number of nosepokes in the side of the corner with quinine solution and increased the number of nosepokes in the side of the corner with tap water, whereas MMP- $9^{-I-}$ mice only decreased the number of nosepokes in the side of the corner with quinine solution: one-way ANOVA (genotype) with repeated measures (session) for tap water: genotype $\times \operatorname{session}\left(F_{(2,28)}=4.74, p<0.02\right.$; post hoc LSD Fisher tests, $\left.p<0.01\right)$.J, Both MMP- $9^{+/+}$and MMP- $9^{-1-}$ mice drank significantly more sweetened water than tap water, reflected by the number of licks. $K_{,}$Both MMP- $9^{+/+}$and MMP- $-9^{-/-}$mice clearly distinguished between the quinine solution and plain water, reflected by the number of licks on the bottle that contained bitter versus tap water. The numbers of licks on the bottles that contained different solutions on the subsequent days of training were compared using one-way ANOVA (genotype) with repeated measures (session $\times$ drinking solution), followed by the Fisher LSD test. PRE, Day that preceded training; DAY1, DAY2, and DAY3, the first, second, and third days of training, respectively. Error bars indicate SEM. ${ }^{*} p<0.05 .{ }^{* *} p<0.01 .{ }^{* * *} p<0.001$. 
A

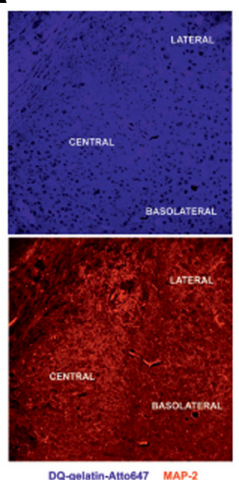

B
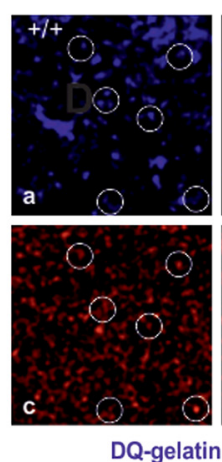
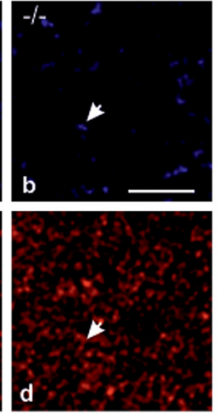

DQ-gelatin PSD-95

D

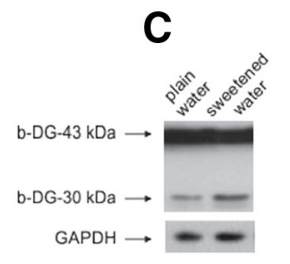

E

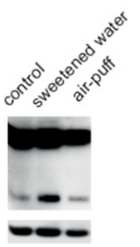

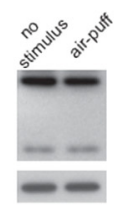

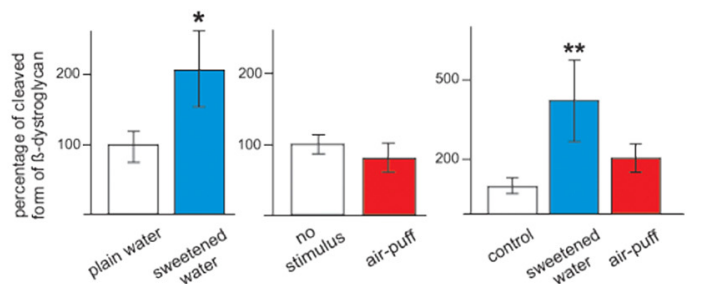

Figure 3. MMP-9 is present in the amygdala, postsynaptically active on excitatory synapses in the CeA and activated after exposure to appetitive stimulation. $\boldsymbol{A}$, In situ zymography (see Materials and Methods) reveals a low level of gelatinolytic activity throughout the neuropil of the amygdala. $\boldsymbol{B}$, Excitatory synapses marked for PSD95 (red) and foci of gelatinolytic activity (blue) can be observed in the CeA in MMP-9 ${ }^{+/+}$mice (Ba,c, collocalization marked with white circles) and are largely missing from MMP-9 ${ }^{-/-}$mice (Bb,d, apparent collocalization marked with white arrows). A limited number of gelatinase-positive spots in MMP-9 ${ }^{-1-}$ mice may reflect the presence of astrocyte-derived MMP-2 activity. Scale bars, $5 \mu \mathrm{m}$. $\boldsymbol{C}-\boldsymbol{E}$, Markedly elevated $\beta$-DG cleavage, reflecting enhanced neuronal MMP-9 activity (Michaluk et al., 2007), evoked by appetitive exposure. The mice were subjected to either appetitive or aversive stimulation and compared with appropriate controls. C, After appetitive training, the accumulation of the $30 \mathrm{kDa}$ cleavage product of $\beta$-DG was found, when the entire amygdala was subjected to the immunoblot analysis (two-way ANOVA [group $\times$ gel], group effect: $\left.F_{(1,9)}=6.47, p<0.05\right)$. $\boldsymbol{D}$, In contrast, increased MMP-9 activity was not observed, in the entire amygdala, after exposure to aversive stimulation. $\boldsymbol{E}$, In the manually dissected CeA, increased levels of $\beta$-DG were observed only in mice subjected to place preference learning but not in mice subjected to place avoidance training compared with the control group ( $p<0.01$, Mann-Whitney $U$ test). The results are expressed as a percentage of the control level of the cleaved form of $\beta$-DG. Error bars indicate SEM. ${ }^{*} p<0.05$, compared with respective control groups. ${ }^{* *} p<0.01$, compared with respective control groups. Five to eight mice were used for each group.

day performance, as well as the learning curves were compared (Fig. 2E,F). Interestingly, further analysis showed that MMP$9^{+1+}$ mice reduced in parallel the number of nosepokes in the side of the corner with quinine solution and increased the number of nosepokes in the side of the corner with tap water, whereas MMP- $9^{-1-}$ mice only decreased the number of nosepokes in the side of the corner with quinine solution and did not increase the number of nosepokes in the other side (Fig. $2 \mathrm{H}, \mathrm{I}$ ). These results indicate that MMP- $9^{-/-}$mice were able to acquire an aversive, but not appetitive, aspect of the task.

To test whether the observed impairment of appetitively motivated discrimination learning could be attributable to either reduced thirst or impaired taste discrimination, the numbers of licks on the bottles that contained different solutions on the subsequent days of training were analyzed for MMP- ${ }^{+/+}$and MMP-9 $9^{-1-}$ mice. The animals of both genotypes clearly distinguished between the sucrose or quinine solutions and tap water, as shown in Figure 2J, $K$.

Because differences in general activity could potentially influence the obtained results, we compared the numbers of visits in the corners in both genotypes during the learning phase and the period that preceded training. The significant differences in activity between genotypes were limited to the period after the introduction of sweetened water and the corner that provided access to water. During the $24 \mathrm{~h}$ period that preceded the training, general activity measured as the number of visits in all four corners was not significantly different (dark phase: $121.1 \pm 12.8$ for MMP $-9^{+/+}$mice and $93.9 \pm 13.9$ for MMP- $9^{-1-}$ mice; light phase: $31.1 \pm 4.7$ for MMP- $9^{+/+}$mice and $25.0 \pm 5.3$ for MMP$9^{-1-}$ mice). This result suggests that differences in general activity were not the primary cause of the observed differences in the rate of discrimination learning between the two genotypes.

To exclude the possibility that the differences in learning between the genotypes were caused by general sensorimotor or olfactory deficits, we performed rotarod and chocolate-searching tests. We did not observe any differences between MMP- $9^{+/+}$ and MMP- $-9^{-1-}$ mice in these tests. Moreover, the MMP- $9^{+/+}$ mice $(n=21)$ and MMP-9 ${ }^{-/-}$mice $(n=19)$ did not differ in any of the anxiety measures in the open field test (frequency of passing through the center: $4.38 \pm 0.7$ for MMP- $9^{+/+}$mice and $4.53 \pm 0.9 \mathrm{MMP}^{-} 9^{-1-}$ mice; total time spent in the center: $2.89 \pm$ $0.6 \mathrm{~s}$ for MMP $-9^{+/+}$mice and $2.79 \pm 0.7 \mathrm{~s}$ for $\mathrm{MMP}^{+} 9^{-1-}$ mice; latency of the first visit in the center: $101.63 \pm 14.8 \mathrm{~s}$ for MMP$9^{+1+}$ mice and $89.8 \pm 19.0$ s for MMP- $9^{-1-}$ mice).

\section{MMP-9 is activated in the central amygdala after appetitive,} but not aversive, conditioning

MMP-9 has been reported to be expressed in the unstimulated brain ubiquitously at low levels, with various stimuli capable to greatly upregulate its activity (Rivera et al., 2010). However, whether MMP-9 is expressed in the amygdala has not been previously investigated. As a first approach to visualize MMP-9 activity in the amygdala, we used in situ zymography with DQgelatin as a substrate that can be digested by either MMP-9 or MMP-2 to reveal a fluorescent signal. The enzymatic activity was observed throughout the neuropil of the basolateral amygdala and CeA, although a slightly higher level of the activity could be discerned in the medial part of CeA (Fig. 3A).

Because the CeA has previously been implicated in the appetitive learning, including place preference training in the IntelliCages (Knapska et al., 2006, 2007), we next investigated whether MMP- 9 activity could be detected in the CeA and then increased in mice subjected to the place preference learning. MMP-9 activity was previously found at the postsynaptic domains of excitatory synapses in the hippocampus (Wilczynski et al., 2008). To determine the synaptic localization of MMP-9 in the CeA in naive animals, we compared MMP-9 activity and the expression of PSD95, a marker of postsynaptic sites of glutamatergic synapses, and observed the colocalized expression of MMP-9 activity and PSD95 (Fig. 3B). Notably, the gelatinolytic activity at the synapses could be ascribed to MMP-9, as its knock-out markedly diminished the staining (compare Fig. $3 B a$ vs $B b$ ).

To test for the enhanced MMP-9 activity, we have followed sensitive and quantitative immunoblot assay for cleavage of its 
A

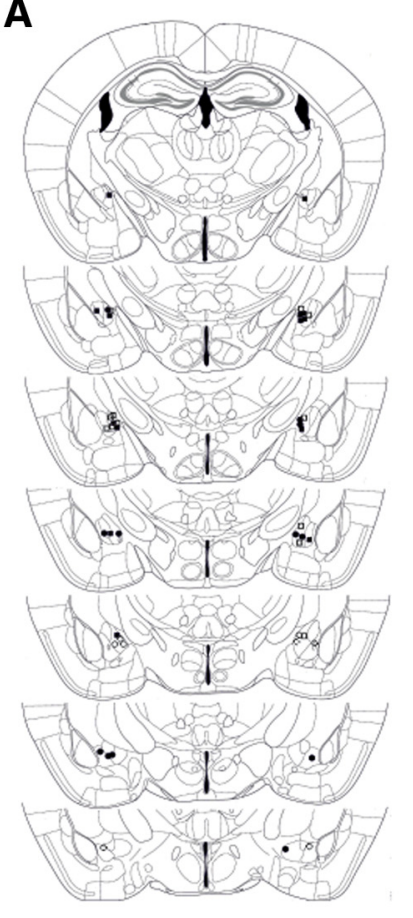

B

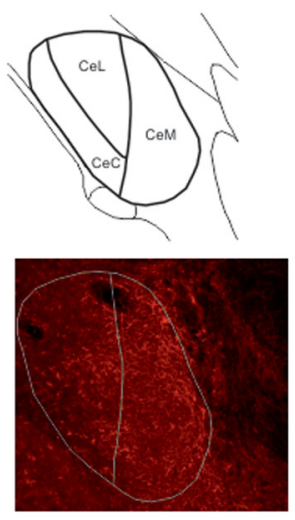

C

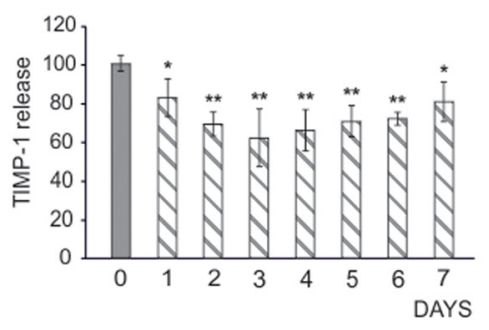

D

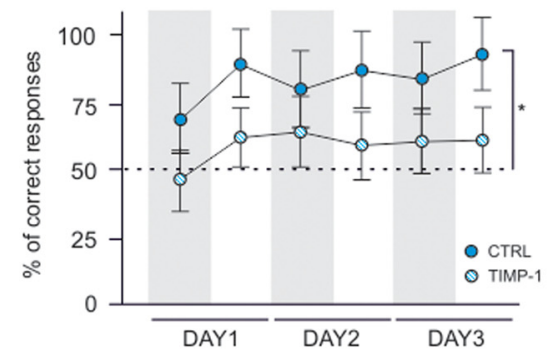

E

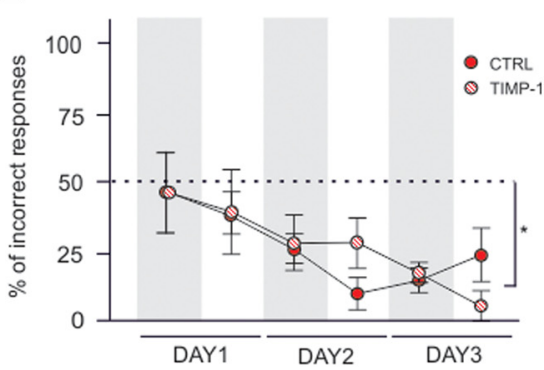

Figure 4. TIMP-1 release from PLGA nanoparticles (NP-TIMP-1) and injection sites. $A$, To inhibit MMP-9 activity in the CeA, the mice were injected with NP-TIMP-1 (TIMP-1 group, sucrose discrimination experiment: filled squares, $n=7$; quinine discrimination experiment: open squares, $n=6$ ). The control animals were injected with empty nanoparticles (CTRL group, sucrose discrimination experiment: filled circles, $n=6$; quinine discrimination experiment: open circles, $n=4$ ). The infusion needle tips for all of the animals included in the analysis are shown. $\boldsymbol{B}$, Top, Schematic picture of the amygdala. Bottom, Distribution of TIMP-1 (red) in the CeA (white contour) after NP-TIMP-1 injection. C, To evaluate sustained release and activity properties of TIMP-1, release studies were performed. The results from the gelatinase assay showed that TIMP- 1 released from NPs was active for at least $7 \mathrm{~d}(n=3)$. Error bars indicate SEM. ${ }^{*} p<0.05$ ( $t$ test). ${ }^{* *} p<$ 0.01 ( $t$ test). D, Mice with local inhibition of MMP-9 activity in the CeA performed much worse in an appetitively motivated discrimination task. Percentage of correct responses (visits that began with the response to the bottle with sweetened water) in the subsequent training phases was significantly different from the level of chance only in the CTRL group (Wilcoxon signed-rank test). Dashed lines indicate the chance level (50\%) of discrimination. $\boldsymbol{E}$, Local inhibition of MMP-9 activity in the CeA did not affect aversively motivated discrimination task. To better present the learning dynamics, the results are presented separately for the day and night phases $(3 \mathrm{~d})$, and gray shaded areas represent the periods of the experiment when the lights were off. Error bars indicate SEM. ${ }^{*} p<0.05$.

substrate, $\beta$-DG in the activated neurons (Michaluk et al., 2007). We first analyzed $\beta$-DG cleavage in the entire amygdala after either appetitive or aversive training and found significant increase in abundance of the cleaved, $30 \mathrm{kDa}$ fragment after exposure to the sweetened water (Fig. $3 C$ ). No such increase could be observed after the exposure to the air-puff (Fig. 3D). Next, we dissected the CeA and subjected to the immunoblot analysis. The increase in the level of the cleaved $\beta$-DG could be demonstrated only after the place preference training (Fig. $3 E$ ).

\section{MMP-9 extracellular activity in the central amygdala is critical for appetitive learning}

To investigate whether MMP-9 activity specifically in the CeA is pivotal for the formation of appetitive memory, we have developed a novel approach aiming at local, extracellular MMP-9 inhibition. Toward this end, NPs that slowly release TIMP-1, the endogenous MMP-9 inhibitor, were produced (NP-TIMP-1). TIMP-1 has been well established as endogenous blocker of MMP- 9 activity, capable of antagonizing also the function of the enzyme in the synaptic plasticity (Okulski et al., 2007). The NP-TIMP-1 were found in vitro to release the active recombinant protein over days and to provide sustained inhibition of MMP-9 (Fig. 4C). After local injection of the NP-TIMP-1 into the CeA (Fig. 4A), the TIMP-1 could be observed extracellularly at least for several days of the experiment duration (Fig. 4B, bottom).
After injections, the animals were trained in the appetitively or aversively motivated discrimination tasks, as described above (Fig. 2A,D). Only the mice with infusion needle tips placed within the CeA were included in the analysis (Fig. 4A). Mice that received TIMP-1 were significantly impaired in appetitively motivated learning, as indicated by the percentage of the correct responses emitted in the subsequent training phases (Fig. 4D). Their performance was significantly different from the chance level (50\%) only in the control group that received an injection of empty nanoparticles into the CeA. Such differences were not observed for the aversively motivated training (Fig. 4E). This result strikingly resembles the one described above for MMP- $9^{-/-}$animals (compare Figs. $4 D$ and $2 B$ with Figs. $4 E$ and $2 E$ ).

\section{Discussion}

This study provides genetic evidence that MMP-9 is required for appetitive, but not aversive, instrumental learning. Furthermore, it shows that MMP-9 activity in the CeA is crucial for this type of learning. First, we demonstrate that unconditional genetic ablation of MMP-9 impairs three kinds of appetitively motivated conditioning (i.e., place preference and discriminative learning in the IntelliCages both with sweetened water and tap water as the reinforcement). On the other hand, lack of MMP-9 does not impair place avoidance and aversively motivated discrimination in the same apparatus. Next, we show that MMP-9 is present in the amygdala and enzymatically active at the excitatory synapses 
in the CeA; moreover, its activity is greatly enhanced in the CeA specifically after the appetitive training. Finally, by blocking extracellular MMP-9 activity by nanoparticle-based release of its inhibitor, recombinant TIMP-1, we reveal that local MMP-9 activity in the CeA is crucial for the appetitive, but not aversive, learning.

Maximizing contact with biologically essential stimuli and minimizing contact with dangerous or noxious stimuli allow an animal to survive. Valence of emotion (i.e., the intrinsic attractiveness or aversiveness of an event, object, or situation) is essential to choose between two main behavioral strategies, approach or withdrawal. Many of these behaviors can be modified by experience. The conditioned place preference and avoidance as well as discrimination of stimuli with different emotional valence are an experimental demonstration of such modifications.

Here we show specific impairment of appetitive instrumental learning that follows selective inhibition of a single extracellular enzymatic activity (MMP-9) in a small subregion of the amygdala (CeA). The local inhibition of MMP-9 activity has been achieved with a novel approach of local delivery of nanoparticles slowly releasing recombinant TIMP-1, an endogenous MMP-9 inhibitor. We have previously shown that excess of TIMP-1 as well as specific MMP-9 chemical inhibitor impair synaptic plasticity in another experimental system (i.e., LTP evoked in the medial prefrontal cortex by subiculum stimulation) (Okulski et al., 2007). As far as the present study is concerned, we think that the TIMP-1 was specifically inhibiting mainly MMP-9 for the following reasons: (1) The available data suggest that MMP-9 is the major MMP available in the brain, especially under behavioral training conditions. (2) The kinetics analyses for binding affinity of TIMP-1 to other MMPs suggest that TIMP-1 has highest dissociation constants $\left(K_{\mathrm{d}}\right)$ for MMP-9 compared with aforementioned other MMPs. It forms tight, noncovalent inhibitory complexes with MMP-9 (with $K_{\mathrm{d}}=10-50 \mathrm{pm}$ ). (3) Finally, we have done gelatinase assay showing the MMP-9 inhibitory activity of our recombinant TIMP-1 released from the NPs.

Our hypothesis about MMP-9's role in the CeA in appetitive learning was based on our previous observations that c-Fos is specifically accumulated in this structure following the appetitively motivated training in the IntelliCage and not activated after place aversion training (Knapska et al., 2006). Incidentally, this observation was also corroborated by findings on appetitive versus aversive instrumental learning of a bar-pressing behavior in rats (Knapska et al., 2006).

The result showing that very space-limited inhibition of a specific enzymatic activity has so marked behavioral consequences as blocking of the appetitive conditioning may appear surprising. However, this result is consistent with experimental data indicating that the CeA plays an important role in reward-related processes and appetitive motivation, including acquisition and expression of conditioned place preference (Kertes et al., 2009; László et al., 2010; Rezayof et al., 2011). Moreover, it has been shown that lesions of the CeA result in an impaired memory for magnitude of food reinforcement (Kesner et al., 1989). Furthermore, the opioid neurotransmission within the CeA has been implicated in guiding reward-seeking behavior (Mahler and Berridge, 2009). Notably, the CeA projects to the dopaminergic ventral tegmental area, which can modulate activity of the nucleus accumbens. The nucleus accumbens and ventral tegmental area, together with the prefrontal cortex, are traditionally regarded as substantial components of the brain reward circuitry (Cardinal et al., 2002). Moreover, the CeA projects to reticular formation nuclei that provide diffuse projection system to the forebrain, in- cluding the dopaminergic ventral tegmental area and substantia nigra pars compacta, the noradrenergic locus ceruleus, the serotonergic raphe nuclei, and basal forebrain cholinergic nuclei, which can modulate function of the prefrontal cortex. Hence, the CeA seems to be well positioned to modulate appetitively motivated operant responses.

On the other hand, previous studies have shown that undisturbed activity of the CeA is necessary for various aspects of aversively motivated behaviors, such as fear conditioning and conditioned place avoidance (Holahan and White, 2004). Specifically, neuronal activity in the mCeA was shown to be required for conditioned fear responses (Ciocchi et al., 2010). In the present study, MMP-9 ${ }^{-1-}$ mice learned aversively motivated operant responses at the same rate as MMP- $9^{+/+}$mice. Similarly, cued fear conditioning is not disrupted in MMP- $9^{-1-}$ mice (Nagy et al., 2006). These results support a notion that several molecular mechanisms associated with different behaviors work concurrently within the same brain structure (Tronson et al., 2012). Moreover, considering the role of MMP-9 in synaptic plasticity, learning, and memory (Meighan et al., 2006; Nagy et al., 2006; Okulski et al., 2007; Wang et al., 2008; Bilousova et al., 2009; Rivera et al., 2010; Michaluk et al., 2011; Huntley, 2012), it seems plausible that its involvement in appetitively motivated learning in the CeA reflects the plastic changes occurring in this structure during this type of training. We cannot also exclude involvement of two distinct neuronal circuits controlling appetitively and aversively motivated behaviors. Such differentiation has been recently shown in the ventral tegmental area, in which two different input-specific circuits generate reward and aversion (Lammel et al., 2012).

In the present study, during appetitive training, the mice were required to associate the sweetened water with either a specific corner within the cage (place preference learning) or with one side of a corner (discrimination learning). The MMP- $9^{-1-}$ mice learned both appetitively motivated tasks much more poorly than MMP- $9^{+/+}$mice. In contrast, such impaired learning was not observed in the place avoidance training and aversively motivated discrimination learning. Importantly, MMP-9 ${ }^{-1-}$ mice drank the same amount of tap water and sweetened water as MMP- $9^{+/+}$animals; therefore, the observed impairment was attributable to neither reduced thirst nor motivation. Interestingly, introduction of the reward caused clearly increased general activity of the MMP $-9^{+/+}$mice, whereas the activity of MMP- $9^{-1-}$ mice was not changed compared with the preceding training phase. Moreover, analysis of the operant responses aimed at getting access to bottles containing quinine versus tap water revealed that both MMP- $9^{-1-}$ and MMP- $9^{+/+}$mice reduced the number of responses punished with bitter taste, but only MMP- $9^{+/+}$ mice increased number of nosepokes rewarded by tap water. These results indicate that MMP-9 ${ }^{-1-}$ mice were able to acquire an aversive, but not appetitive, aspect of the task. Another possibility to account for the impairment of MMP-9 ${ }^{-1-}$ mice in the discrimination learning was that they were not able to associate specific taste with one side of a corner. Then, it would be a deficit related rather to processing of sensory stimuli of specific modality than to motivation. Undisturbed discrimination learning between quinine and water ruled out such interpretation of deficits observed in MMP-9 ${ }^{-/-}$mice. Together, these observations suggest that MMP- $9^{-1-}$ mice are specifically impaired in rewardrelated operant learning. On the other hand, aversively motivated operant learning seems to be undisturbed in MMP- $9^{-1-}$ mice. The central amygdala is also known to mediate anxiety responses (Etkin et al., 2009; Tye et al., 2011). However, the impairments of 
learning observed in MMP-9 $9^{-1-}$ mice cannot be related to changed anxiety level as they did not differ from MMP- $9^{+/+}$in the anxiety-like behavior measured in the open field test. The impairment of learning of MMP-9 ${ }^{-1-}$ mice with tap water reward suggests that the observed deficits are not specifically related to sweetened water. The observation of such impairment for the first nosepoke of each visit additionally corroborates the explanation that the impairment is the result of memory deficits.

Different extracellular proteases have previously been shown to contribute to fear-and anxiety-related responses by facilitating neuronal plasticity in the amygdala (Pawlak et al., 2003; Gogolla et al., 2009; Attwood et al., 2011). The present results show that MMP-9 is involved in appetitively, but not aversively, motivated operant learning processes. This differential function of MMP-9 in learning is matched by its involvement in neuronal plasticity within the CeA. Therefore, our data challenge the notion of similar molecular mechanisms within the amygdala that govern appetitive and aversive learning (Shabel and Janak, 2009). An interesting avenue of research opened by our study might be a more detailed investigation of the amygdala that differentiates the various molecular mechanisms operating within various subdivisions in patients suffering from psychiatric disorders, such as drug and alcohol addiction, major depression, bipolar disorder, and schizophrenia, in whom recent studies have indicated a possible role of MMP-9 (Mash et al., 2007; Rybakowski et al., 2009a, b; Domenici et al., 2010; Samochowiec et al., 2010). It is an important challenge for the forthcoming studies to relate amygdala structure and function with MMP-9 activity and functional gene polymorphisms.

\section{References}

Attwood BK, Bourgognon JM, Patel S, Mucha M, Schiavon E, Skrzypiec AE, Young KW, Shiosaka S, Korostynski M, Piechota M, Przewlocki R, Pawlak R (2011) Neuropsin cleaves EphB2 in the amygdala to control anxiety. Nature 473:372-375. CrossRef Medline

Belova MA, Paton JJ, Morrison SE, Salzman CD (2007) Expectation modulates neural responses to pleasant and aversive stimuli in primate amygdala. Neuron 55:970-984. CrossRef Medline

Bilousova TV, Dansie L, Ngo M, Aye J, Charles JR, Ethell DW, Ethell IM (2009) Minocycline promotes dendritic spine maturation and improves behavioural performance in the fragile X mouse model. J Med Genet 46:94-102. CrossRef Medline

Bossert JM, Stern AL, Theberge FR, Cifani C, Koya E, Hope BT, Shaham Y (2011) Ventral medial prefrontal cortex neuronal ensembles mediate context-induced relapse to heroin. Nat Neurosci 14:420-422. CrossRef Medline

Cardinal RN, Parkinson JA, Lachenal G, Halkerston KM, Rudarakanchana N, Hall J, Morrison CH, Howes SR, Robbins TW, Everitt BJ (2002) Effects of selective excitotoxic lesions of the nucleus accumbens core, anterior cingulate cortex, and central nucleus of the amygdala on autoshaping performance in rats. Behav Neurosci 116:553-567. CrossRef Medline

Chaturvedi M, Figiel I, Sreedhar B, Kaczmarek L (2012) Neuroprotection from tissue inhibitor of metalloproteinase- 1 and its nanoparticles. Neurochem Int 61:1065-1071. CrossRef Medline

Ciocchi S, Herry C, Grenier F, Wolff SB, Letzkus JJ, Vlachos I, Ehrlich I, Sprengel R, Deisseroth K, Stadler MB, Müller C, Lüthi A (2010) Encoding of conditioned fear in central amygdala inhibitory circuits. Nature 468:277-282. CrossRef Medline

Domenici E, Willé DR, Tozzi F, Prokopenko I, Miller S, McKeown A, Brittain C, Rujescu D, Giegling I, Turck CW, Holsboer F, Bullmore ET, Middleton L, Merlo-Pich E, Alexander RC, Muglia P (2010) Plasma protein biomarkers for depression and schizophrenia by multi analyte profiling of case-control collections. PLoS One 5:e9166. CrossRef Medline

Etkin A, Prater KE, Schatzberg AF, Menon V, Greicius MD (2009) Disrupted amygdalar subregion functional connectivity and evidence of a compensatory network in generalized anxiety disorder. Arch Gen Psychiatry 66:1361-1372. CrossRef Medline

Everitt BJ, Cardinal RN, Parkinson JA, Robbins TW (2003) Appetitive be- havior: impact of amygdala-dependent mechanisms of emotional learning. Ann N Y Acad Sci 985:233-250. CrossRef Medline

Galsworthy MJ, Amrein I, Kuptsov PA, Poletaeva II, Zinn P, Rau A, Vyssotski A, Lipp HP (2005) A comparison of wild-caught wood mice and bank voles in the IntelliCage: assessing exploration, daily activity patterns and place learning paradigms. Behav Brain Res 157:211-217. CrossRef Medline

Ganguly K, Rejmak E, Mikosz M, Nikolaev E, Knapska E, Kaczmarek L (2013) Matrix metalloproteinase (MMP)-9 transcription in mouse brain induced by fear learning. J Biol Chem 288:20978-20991. CrossRef Medline

Gawlak M, Górkiewicz T, Gorlewicz A, Konopacki FA, Kaczmarek L, Wilczynski GM (2009) High resolution in situ zymography reveals matrix metalloproteinase activity at glutamatergic synapses. Neuroscience 158 : 167-176. CrossRef Medline

Gogolla N, Caroni P, Lüthi A, Herry C (2009) Perineuronal nets protect fear memories from erasure. Science 325:1258-1261. CrossRef Medline

Holahan MR, White NM (2004) Intra-amygdala muscimol injections impair freezing and place avoidance in aversive contextual conditioning. Learn Mem 11:436-446. CrossRef Medline

Holland PC, Gallagher M (2004) Amygdala-frontal interactions and reward expectancy. Curr Opin Neurobiol 14:148-155. CrossRef Medline

Humphrey T (1936) The telencephalon of the bat: I. The non-cortical nuclear masses and certain pertinent fiber connections. J Comp Neurol 65:603-711. CrossRef

Huntley GW (2012) Synaptic circuit remodelling by matrix metalloproteinases in health and disease. Nat Rev Neurosci 13:743-757. CrossRef Medline

Jaworski J, Biedermann IW, Lapinska J, Szklarczyk A, Figiel I, Konopka D, Nowicka D, Filipkowski RK, Hetman M, Kowalczyk A, Kaczmarek L (1999) Neuronal excitation-driven and AP-1-dependent activation of tissue inhibitor of metalloproteinases-1 gene expression in rodent hippocampus. J Biol Chem 274:28106-28112. CrossRef Medline

Johansen JP, Cain CK, Ostroff LE, LeDoux JE (2011) Molecular mechanisms of fear learning and memory. Cell 147:509-524. CrossRef Medline

Johnston JB (1923) Further contributions to the study of the evolution of the forebrain. J Comp Neurol 35:337-481. CrossRef

Kaczmarek L (1993) Molecular biology of vertebrate learning: is c-fos a new beginning? J Neurosci Res 34:377-381. CrossRef Medline

Kaczmarek L, Lapinska-Dzwonek J, Szymczak S (2002) Matrix metalloproteinases in the adult brain physiology: a link between c-Fos, AP-1 and remodeling of neuronal connections? EMBO J 21:6643-6648. CrossRef Medline

Kertes E, László K, Berta B, Lénárd L (2009) Positive reinforcing effects of substance $\mathrm{P}$ in the rat central nucleus of amygdala. Behav Brain Res 205: 307-310. CrossRef Medline

Kesner RP, Walser RD, Winzenried G (1989) Central but not basolateral amygdala mediates memory for positive affective experiences. Behav Brain Res 33:189-195. CrossRef Medline

Knapska E, Walasek G, Nikolaev E, Neuhäusser-Wespy F, Lipp HP, Kaczmarek L, Werka T (2006) Differential involvement of the central amygdala in appetitive versus aversive learning. Learn Mem 13:192-200. CrossRef Medline

Knapska E, Radwanska K, Werka T, Kaczmarek L (2007) Functional internal complexity of amygdala: focus on gene activity mapping after behavioral training and drugs of abuse. Physiol Rev 87:1113-1173. CrossRef Medline

Koya E, Golden SA, Harvey BK, Guez-Barber DH, Berkow A, Simmons DE, Bossert JM, Nair SG, Uejima JL, Marin MT, Mitchell TB, Farquhar D, Ghosh SC, Mattson BJ, Hope BT (2009) Targeted disruption of cocaineactivated nucleus accumbens neurons prevents context-specific sensitization. Nat Neurosci 12:1069-1073. CrossRef Medline

Kuzniewska B, Rejmak E, Malik AR, Jaworski J, Kaczmarek L, Kalita K (2013) Brain-derived neurotrophic factor induces matrix metalloproteinase 9 expression in neurons via the serum response factor/c-Fos pathway. Mol Cell Biol 33:2149-2162. CrossRef Medline

Lammel S, Lim BK, Ran C, Huang KW, Betley MJ, Tye KM, Deisseroth K, Malenka RC (2012) Input-specific control of reward and aversion in the ventral tegmental area. Nature 491:212-217. CrossRef Medline

László K, Tóth K, Kertes E, Péczely L, Lénárd L (2010) The role of neurotensin in positive reinforcement in the rat central nucleus of amygdala. Behav Brain Res 208:430-435. CrossRef Medline 
Liu X, Ramirez S, Pang PT, Puryear CB, Govindarajan A, Deisseroth K, Tonegawa S (2012) Optogenetic stimulation of a hippocampal engram activates fear memory recall. Nature 484:381-385. CrossRef Medline

Mahler SV, Berridge KC (2009) Which cue to "want?" Central amygdala opioid activation enhances and focuses incentive salience on a prepotent reward cue. J Neurosci 29:6500-6513. CrossRef Medline

Mash DC, ffrench-Mullen J, Adi N, Qin Y, Buck A, Pablo J (2007) Gene expression in human hippocampus from cocaine abusers identifies genes which regulate extracellular matrix remodeling. PLoS One 2:e1187. CrossRef Medline

McDonald A (1992) Cell types and intrinsic connections of the amygdala. In: The amygdale: neurobiological aspects of emotion, memory, and mental dysfunction, pp 67-96. New York: Wiley.

Meighan SE, Meighan PC, Choudhury P, Davis CJ, Olson ML, Zornes PA, Wright JW, Harding JW (2006) Effects of extracellular matrixdegrading proteases matrix metalloproteinases 3 and 9 on spatial learning and synaptic plasticity. J Neurochem 96:1227-1241. CrossRef Medline

Michaluk P, Kolodziej L, Mioduszewska B, Wilczynski GM, Dzwonek J, Jaworski J, Gorecki DC, Ottersen OP, Kaczmarek L (2007) Betadystroglycan as a target for MMP-9, in response to enhanced neuronal activity. J Biol Chem 282:16036-16041. CrossRef Medline

Michaluk P, Wawrzyniak M, Alot P, Szczot M, Wyrembek P, Mercik K, Medvedev N, Wilczek E, De Roo M, Zuschratter W, Muller D, Wilczynski GM, Mozrzymas JW, Stewart MG, Kaczmarek L, Wlodarczyk J (2011) Influence of matrix metalloproteinase MMP-9 on dendritic spine morphology. J Cell Sci 124:3369-3380. CrossRef Medline

Morrison SE, Salzman CD (2010) Re-valuing the amygdala. Curr Opin Neurobiol 20:221-230. CrossRef Medline

Murray EA (2007) The amygdala, reward and emotion. Trends Cogn Sci 11:489-497. CrossRef Medline

Nagy V, Bozdagi O, Matynia A, Balcerzyk M, Okulski P, Dzwonek J, Costa RM, Silva AJ, Kaczmarek L, Huntley GW (2006) Matrix metalloproteinase- 9 is required for hippocampal late-phase long-term potentiation and memory. J Neurosci 26:1923-1934. CrossRef Medline

Okulski P, Jay TM, Jaworski J, Duniec K, Dzwonek J, Konopacki FA, Wilczynski GM, Sánchez-Capelo A, Mallet J, Kaczmarek L (2007) TIMP-1 abolishes MMP-9-dependent long-lasting long-term potentiation in the prefrontal cortex. Biol Psychiatry 62:359-362. CrossRef Medline

Paton JJ, Belova MA, Morrison SE, Salzman CD (2006) The primate amygdala represents the positive and negative value of visual stimuli during learning. Nature 439:865-870. CrossRef Medline

Pawlak R, Magarinos AM, Melchor J, McEwen B, Strickland S (2003) Tissue plasminogen activator in the amygdala is critical for stress-induced anxiety-like behavior. Nat Neurosci 6:168-174. CrossRef Medline

Pitkänen A, Jolkkonen E, Kemppainen S (2000) Anatomic heterogeneity of the rat amygdaloid complex. Folia Morphol (Warsz) 59:1-23. Medline

Rezayof A, Sardari M, Zarrindast MR, Nayer-Nouri T (2011) Functional interaction between morphine and central amygdala cannabinoid CB1 receptors in the acquisition and expression of conditioned place preference. Behav Brain Res 220:1-8. CrossRef Medline

Riccio A, Li Y, Moon J, Kim KS, Smith KS, Rudolph U, Gapon S, Yao GL, Tsvetkov E, Rodig SJ, Van't Veer A, Meloni EG, Carlezon WA Jr, Bolshakov VY, Clapham DE (2009) Essential role for TRPC5 in amygdala function and fear-related behavior. Cell 137:761-772. CrossRef Medline

Rivera S, Khrestchatisky M, Kaczmarek L, Rosenberg GA, Jaworski DM (2010) Metzincin proteases and their inhibitors: foes or friends in nervous system physiology? J Neurosci 30:15337-15357. CrossRef Medline
Roberts GW (1992) Neuropeptides: cellular morphology, major pathways, and functional considerations. In: The amygdale: neurobiological aspects of emotion, memory, and mental dysfunction, pp 115-142. New York: Wiley.

Rybakowski JK, Skibinska M, Kapelski P, Kaczmarek L, Hauser J (2009a) Functional polymorphism of the matrix metalloproteinase-9 (MMP-9) gene in schizophrenia. Schizophr Res 109:90-93. CrossRef Medline

Rybakowski JK, Skibinska M, Leszczynska-Rodziewicz A, Kaczmarek L, Hauser J (2009b) Matrix metalloproteinase-9 gene and bipolar mood disorder. Neuromolecular Med 11:128-132. CrossRef Medline

Rylski M, Amborska R, Zybura K, Michaluk P, Bielinska B, Konopacki FA, Wilczynski GM, Kaczmarek L (2009) JunB is a repressor of MMP-9 transcription in depolarized rat brain neurons. Mol Cell Neurosci 40:98110. CrossRef Medline

Sah P, Faber ES, Lopez De Armentia M, Power J (2003) The amygdaloid complex: anatomy and physiology. Physiol Rev 83:803-834. CrossRef Medline

Samochowiec A, Grzywacz A, Kaczmarek L, Bienkowski P, Samochowiec J, Mierzejewski P, Preuss UW, Grochans E, Ciechanowicz A (2010) Functional polymorphism of matrix metalloproteinase-9 (MMP-9) gene in alcohol dependence: family and case control study. Brain Res 1327:103106. CrossRef Medline

Savonenko A, Filipkowski RK, Werka T, Zielinski K, Kaczmarek L (1999) Defensive conditioning-related functional heterogeneity among nuclei of the rat amygdala revealed by c-Fos mapping. Neuroscience 94:723-733. CrossRef Medline

Schoenbaum G, Chiba AA, Gallagher M (1998) Orbitofrontal cortex and basolateral amygdala encode expected outcomes during learning. Nat Neurosci 1:155-159. CrossRef Medline

Shabel SJ, Janak PH (2009) Substantial similarity in amygdala neuronal activity during conditioned appetitive and aversive emotional arousal. Proc Natl Acad Sci U S A 106:15031-15036. CrossRef Medline

Shumyatsky GP, Malleret G, Shin RM, Takizawa S, Tully K, Tsvetkov E, Zakharenko SS, Joseph J, Vronskaya S, Yin D, Schubart UK, Kandel ER, Bolshakov VY (2005) stathmin, a gene enriched in the amygdala, controls both learned and innate fear. Cell 123:697-709. CrossRef Medline

Tronson NC, Corcoran KA, Jovasevic V, Radulovic J (2012) Fear conditioning and extinction: emotional states encoded by distinct signaling pathways. Trends Neurosci 35:145-155. CrossRef Medline

Tye KM, Prakash R, Kim SY, Fenno LE, Grosenick L, Zarabi H, Thompson KR, Gradinaru V, Ramakrishnan C, Deisseroth K (2011) Amygdala circuitry mediating reversible and bidirectional control of anxiety. Nature 471:358-362. CrossRef Medline

Wang XB, Bozdagi O, Nikitczuk JS, Zhai ZW, Zhou Q, Huntley GW (2008) Extracellular proteolysis by matrix metalloproteinase- 9 drives dendritic spine enlargement and long-term potentiation coordinately. Proc Natl Acad Sci U S A 105:19520-19525. CrossRef Medline

Wilczynski GM, Konopacki FA, Wilczek E, Lasiecka Z, Gorlewicz A, Michaluk P, Wawrzyniak M, Malinowska M, Okulski P, Kolodziej LR, Konopka W, Duniec K, Mioduszewska B, Nikolaev E, Walczak A, Owczarek D, Gorecki DC, Zuschratter W, Ottersen OP, Kaczmarek L (2008) Important role of matrix metalloproteinase 9 in epileptogenesis. J Cell Biol 180:1021-1035. CrossRef Medline

Wurtz RH, Olds J (1963) Amygdaloid stimulation and operant reinforcement in the rat. J Comp Physiol Psychol 56:941-949. CrossRef Medline 